\title{
A walk in the park with a curious dog on a long leash...
}

The creative installation entitled Visual Appropriations and Rewritings invited students in the Brock University courses "Intermediate Painting" and "Interpretive and Critical Writing in the Arts" to contemplate well-known artists' writings and offer a visual response. The resulting show was a marriage between poetic text and provocative visual art that surrounded the viewer, creating a panoramic installation in Rodman Hall's Studio Gallery. The kaleidoscopic interface of image and word was unified and punctuated by the introduction of a large geometric shapes and the pulsing glow of bright yellow that pervaded the room.

Viewers moving through the exhibition, for orientation, may have migrated to the text panels written by students, presented on yellow panels. The fragmented writings, however, did not provide secure mooring for the seeker, but, instead opened up poetic episodes in an untethered narrative. One's predilection for the safety of linear logic may have prompted a search for association and links between texts, but soon a comfort set in, allowing the words to prompt random visual images in our minds that ricocheted off the visual art in the exhibition. "Haze has set in; the viewing pleasure begins" reads one of the panels. Many other texts referred obliquely to visual cues in the room or alluded to the prescribed state-of-mind conducive to good viewing: "strategically placed blotting", "markings seem obsessive and crazed", "Let us not forget what is unwritten and sublime", " in a blank space away from the rest of the world."

The disparate selection of visual art on display encompassed various unframed objects, small and ephemeral. The works were sometimes overlapping, occluding parts of one drawing or painting under the flap of another. All of the various pieces were held by magnets in random groupings that became constellations, visually interacting with the large yellow painted canvases that formed islands of colour. The canvas backdrops were visual territories that created borders between the wall surface and the zones of amplified yellow which heightened stimulus in the act of viewing. Often works migrated to the edge of a yellow zone, hovering on a border enjoying the tension at the edge of things. Works were not doodles, but some embodied the excitement of exploring the potential of materials. Others were representations of something recognizable, a 
face or flower that translated into memory, thought and word, looping back to the poetry that fills the spaces between.

This wonderful juxtaposition of imagery and prose gave viewers a sense of the delicate tension that meaning provides in associating the visual with the written word. There was evidence of play and experimentation in this logic-laboratory, serving to reinforce for the viewer the strong thread that hangs between what we see and what we read. The destination is not nearly as important as the journey. The tension on that thin line is a reassuring tautness that reminds one of the pleasures of a walk in the park with a curious dog on a long leash, prompting a flurry of furtive excursions through a yellow-infused bright and sunny day.

Stuart Reid, Director/Curator, Rodman Hall Art Centre/Brock University 